\title{
ARTICLE
}

\section{Assessment of potential options for conditional reuse of materials from nuclear installation decommissioning}

\author{
Matej Zachar $^{\mathrm{a}^{*}}$, Vladimir Daniska ${ }^{\mathrm{a}}$, Frantisek Ondra ${ }^{\mathrm{a}}$, Jozef Pritrsky ${ }^{\mathrm{a}}$ and Vladimir Necas ${ }^{\mathrm{b}}$ \\ ${ }^{a}$ DECOM, a.s., Sibirska 1, 91701 Trnava, Slovakia; ${ }^{b}$ Slovak University of Technology in Bratislava, Faculty of Electrical \\ Engineering and Information Technology, Ilkovicova 3, 812 19, Bratislava, Slovakia
}

\begin{abstract}
The nuclear installation decommissioning process is characterized by production of large amount of radioactive materials to be managed. The materials with radioactivity slightly above the unconditional release levels could be released conditionally for a specific industrial application in accordance with beforehand developed and evaluated scenario. This evaluation has to ensure that the limits for radiation exposure of workers and the public will not be exceeded. The paper gives an overview of representative options (scenarios) for reuse of conditionally released steel materials and recycled concrete from decommissioning. The main aim of the paper is to present the developed complex methodology for assessment of these options and its implementation to the relevant calculation tools. The first step in the methodology procedure is the identification of the activities which could lead to the exposure of the public or workers. For defined activities the external exposure of workers and the public is evaluated using the Visiplan 3D ALARA Planning tool. The internal exposure analysis is mainly based on the models for migration of radionuclides in the environment calculated in the GoldSim code. Based on the results of exposure evaluation, the critical exposure pathway is determined and conditional release levels of individual radionuclides are derived. Finally the amount and radioactivity of materials from decommissioning, fulfilling the limits for conditional reuse, are calculated in the decommissioning planning code OMEGA [1].
\end{abstract}

Keywords: decommissioning; conditional release and reuse; external exposure; internal exposure; conditional release levels; Visiplan 3D ALARA; GoldSim; OMEGA code

\section{Introduction}

As a result of decommissioning activities a wide range of material (waste) types with various physical, chemical, radiological and toxic characteristics arises. All the activities done in the decommissioning materials or waste management process are aimed to achieve:

- Release the materials to the environment for reuse;

- Safe isolation of the non-releasable materials from the environment within the radioactive waste (RAW) repository barriers.

The releasing process is based on the concept of triviality of exposure, generally taken to mean that radiation risks to individuals and collective radiological impact, caused by the released material, is sufficiently low. In quantitative terms, the mentioned state is related to the stipulation that the effective dose expected to be incurred by any member of the public due to the released materials is of the order of $10 \mu \mathrm{Sv}$ or less during one year. Collective effective dose (sum of all of the individual doses to members of the public) is proposed to be lower than 1 manSv/year [2,3].

Internationally recommended principle for dose constraints $10 \mu \mathrm{Sv} /$ year (individual effective dose) / 1 manSv/year (collective effective dose) [3] creates a basis for derivation of unconditional release levels. The unconditionally released materials could be reused in the environment without any restriction from radiological point of view.

On the other hand, there is a possibility to release the materials conditionally i.e. for specific application but the dose constraint $10 \mu \mathrm{Sv} /$ year has to be followed. The dose constraint could be higher e.g. Slovak legislation [4] defines the limit $50 \mu \mathrm{Sv} /$ year considering specific conditions.

The definition of specific options for conditional reuse of materials followed by their assessment aimed to demonstrate the applicability of this concept is the main goal of the research project CONRELMAT (CONditional RELease of MATerials). Its main features are discussed in this paper.

*Corresponding author. Email: zachar@decom.sk 
2. Potential options for conditional reuse of decommissioning materials

Definition of the options for conditional reuse of decommissioning materials in the environment is the first logical step in the evaluation process. Following criteria were set for constructions and structures:

- Long term stability and long term preservation of original design characteristics of the constructions or structures;

- Long term planned use (several decades);

- Materials are either embedded into non-radioactive construction materials (e.g. reinforcement bars in concrete) or limited access of the public is expected due to construction features and conditions of use.

Two material types from decommissioning are considered to be optimal for further conditional reuse:

- Recycled steel in the form of melted ingots;

- Recycled concrete.

Taking into account the mentioned criteria and material types, following typical representative applications or structures are considered and assessed in the project CONRELMAT:

- Manufacturing of metallurgical construction elements;

- Application in railways construction;

- Bridges construction (railway, road - steel);

- High-voltage pylons (electricity distribution grids);

- Assembled steel halls;

- Large-size pipelines;

- Tunnel constructions (steel construction elements);

- Prefabricated and monolithic reinforced concrete structures (reinforcement bars);

- Retention tanks (reinforcement bars);

- Dam structures (reinforcement bars);

- Motorway scenario (road embankment) - only one scenario with application of recycled concrete;
- Big storage tanks in NPP controlled area.

The conditional reuse of steel or concrete in the industrial applications assumes the releasing of materials to the environment. The recycling before release (e.g. melting process) is considered to be done inside the nuclear sites.

But there is also a possibility to reuse such materials only in the nuclear industry. It means that all steps of processing up to reuse are done within the nuclear site and the release campaigns are not necessary. What is more, it seems to be also a publicly more accepted solution for managing the decommissioning materials. The construction of big storage stainless steel tanks is considered as option for the project purposes. Other examples for reusing the materials within the nuclear industry are fabrication of waste packages (drums, casks), incorporation of them into reinforced concrete structures of RAW repositories or manufacturing of waste processing equipment (supercompactor) [5].

\section{Methodology for scenarios assessment}

This section describes in details the methodology for assessment of the options for conditional reuse of materials. The methodology could be defined in following steps (Figure 1) [6,7]:

A. Definition of final (target) structures for application of conditionally released materials (e.g. bridge, tunnel) i.e. characterization of their end state.

B. Identification of activities during whole life cycle of the structures. Starting from recycling of decommissioning materials (melting of steel, recycling of building materials), continuing with manufacturing of construction elements (reinforcement bars, rolled steel sheets), construction of structures itself and ending with operation and maintenance - including the possible interaction of the public with the structures. Tasks A and B are the

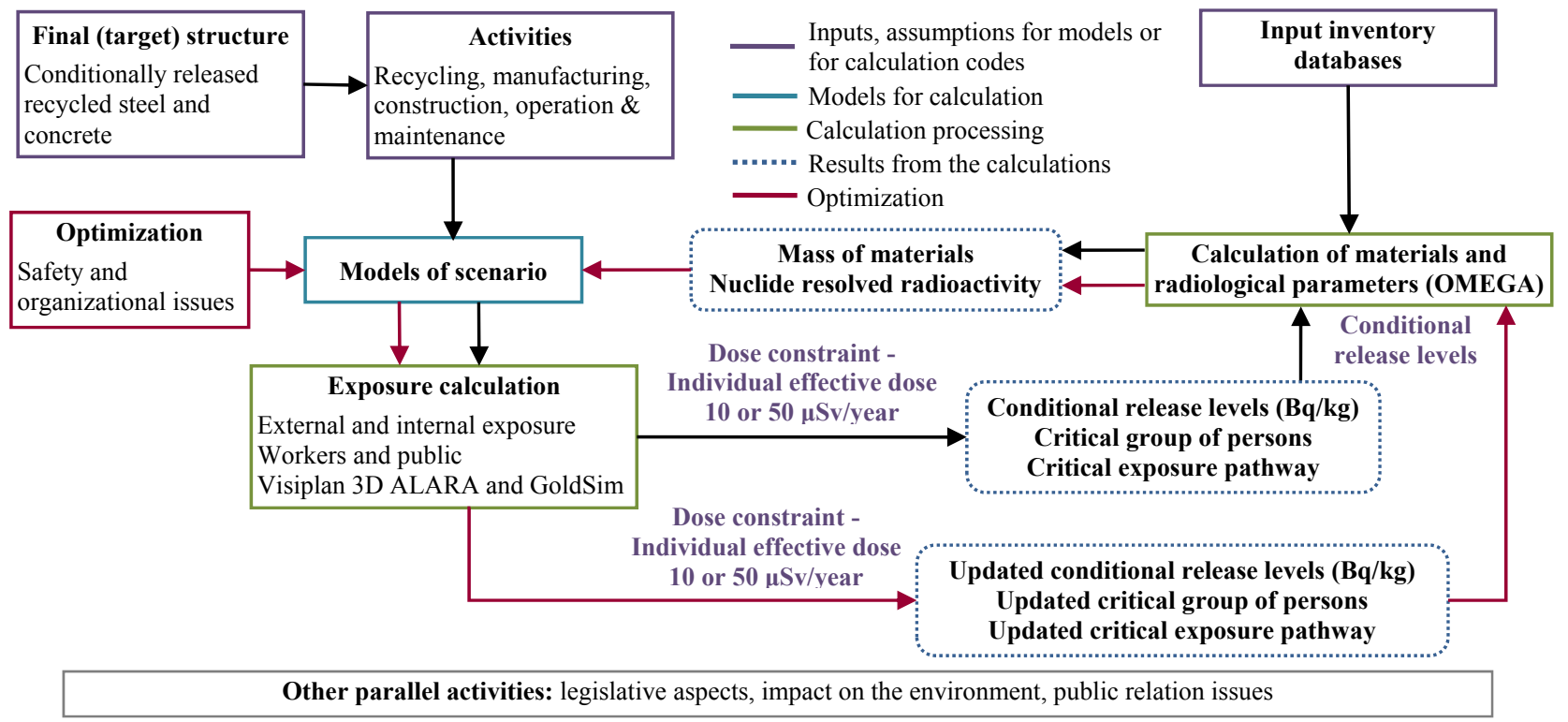

Figure 1. Methodology for assessment of scenarios for conditional reuse of materials. 
inputs for the models creation (task C).

C. Creation of the models used for exposure calculation using relevant calculation tools (task D).

D. Evaluation of exposure of workers and the public during whole life cycle of the structures and considering all relevant exposure pathways - external exposure and internal exposure (Figure 2). For calculation of individual effective dose caused by gamma emitters (external exposure) the computer code Visiplan 3D ALARA is used (short-term periods). The point-kernel integration method is applied. The Monte Carlo simulation software code GoldSim is used for assessment of long-term impact (external and internal exposure). Calculation is based on the modeling of structures degradation processes and modeling of radionuclides migration from the structures through the environment. The interim exposure was, in some cases, calculated based on the parameters and approaches applied in international recommendation [8]. The target values of individual effective dose not to be exceeded are 10 or 50 $\mu \mathrm{Sv} /$ year. These dose constraints determined the conditional release levels for individual radionuclides. It means the maximum concentration $(\mathrm{Bq} / \mathrm{kg})$ of radioactivity in the materials to allow them to be reused in accordance with the defined scenario conditions. The critical group of persons (e.g. construction workers) and critical exposure pathway are also determined in this step.

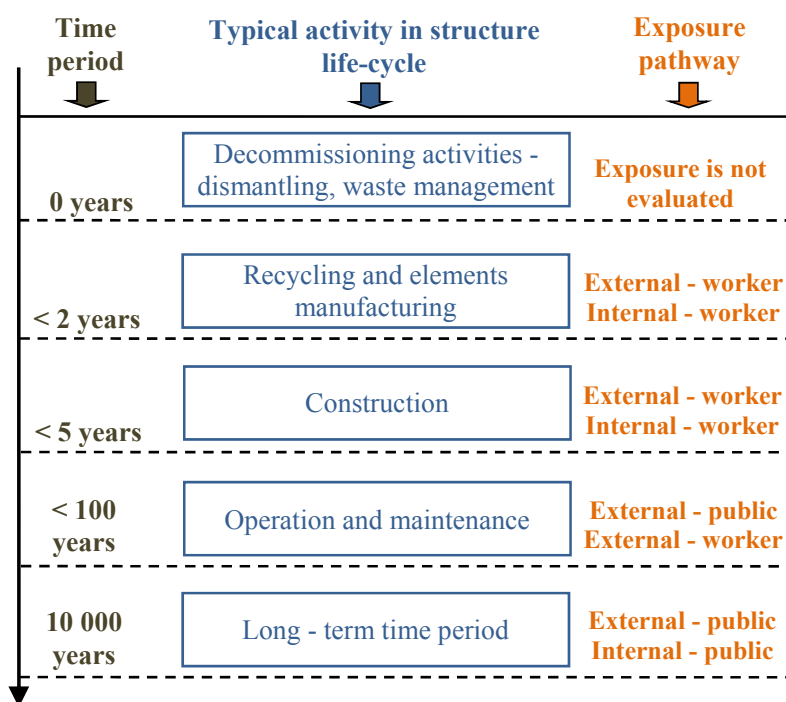

Figure 2. Exposure pathways during life- cycle of structure.

E. Calculation of material and radiological parameters of conditionally released materials. The decommissioning planning code OMEGA (developed in the DECOM company) with newly implemented calculation stream evaluating the conditional release is used [9]. The necessary inputs for calculation are:

- Input inventory database based on the real databases of nuclear installations in Slovakia;

- Conditional release levels as a result of the previous steps of assessment (task D).
The outputs from the OMEGA calculation run are:

- Mass of materials to be released conditionally;

- Nuclide resolved radioactivity of materials.

F. Optimization of the models by improving safety or organizational means of the scenarios (e.g. additional shielding, organization of working shifts). The exposure calculation (task D) is done again and the updated conditional release levels are obtained. They are loaded to the OMEGA but the data in the input inventory databases remains unchanged. Another OMEGA calculation run brings updated outputs mass and radioactivity of materials. The optimization could be done until it seems reasonable.

G. Other parallel activities with no impact on the results of the calculations such as legislative aspects of conditional release; impact on the environment, public relation issues.

\section{Preliminary results of evaluation}

In Table 1, the preliminary results for the option of high-voltage pylons are presented to demonstrate the feasibility of the presented methodology. Under the scenario, five pylons are considered; dose constraint $10 \mu \mathrm{Sv} /$ year and unconditional release levels are defined according to the Slovak legislation [4]. Proposed conditional release levels as well as critical exposure pathway are presented as results.

Table 1. Results for five high-voltage pylons option.

\begin{tabular}{cccc}
\hline Nuclide & $\begin{array}{c}\text { Unconditional } \\
\text { release level } \\
(\mathbf{B q} / \mathbf{k g})\end{array}$ & $\begin{array}{c}\text { Derived } \\
\text { conditional release } \\
\text { level } \mathbf{( B q} / \mathbf{k g})\end{array}$ & $\begin{array}{c}\text { Critical exposure } \\
\text { pathway }\end{array}$ \\
\hline${ }^{14} \mathrm{C}$ & $3.00 \mathrm{E}+05$ & $1.60 \mathrm{E}+06$ & Ingestion \\
${ }^{55} \mathrm{Fe}$ & $3.00 \mathrm{E}+05$ & $3.62 \mathrm{E}+09$ & Skin Exposure \\
${ }^{60} \mathbf{C o}$ & $\mathbf{3 . 0 0 E}+\mathbf{0 2}$ & $\mathbf{6 . 0 0 E}+\mathbf{0 2}$ & External \\
${ }^{63} \mathrm{Ni}$ & $3.00 \mathrm{E}+06$ & $4.00 \mathrm{E}+09$ & Ingestion \\
${ }^{90} \mathrm{Sr}$ & $3.00 \mathrm{E}+03$ & $5.89 \mathrm{E}+06$ & Ingestion \\
${ }^{94} \mathbf{N b}$ & $\mathbf{3 . 0 0 E}+\mathbf{0 2}$ & $\mathbf{7 . 4 1 E}+\mathbf{0 2}$ & External \\
${ }^{137} \mathrm{Cs}$ & $3.00 \mathrm{E}+02$ & $2.00 \mathrm{E}+03$ & External \\
${ }^{239} \mathrm{Pu}$ & $3.00 \mathrm{E}+02$ & $7.43 \mathrm{E}+03$ & Inhalation \\
${ }^{241} \mathrm{Am}$ & $3.00 \mathrm{E}+02$ & $3.03 \mathrm{E}+06$ & Inhalation \\
\hline
\end{tabular}

For the high-voltage pylon option, the external exposure of the construction worker seems to be a critical exposure pathway. From the list of selected radionuclides (Table 1), the conditional release levels for gamma emitters ${ }^{60} \mathrm{Co},{ }^{94} \mathrm{Nb}$ are the most restrictive i.e. about two times higher than unconditional release level.

The results for the other options, as defined in section 2 , are proposed to be presented in a similar way in the frame of project CONRELMAT. The results for some of them could be found also in other papers presented in the ICRS-12 conference [7,10,11].

Taking into account up-to-date evaluated options in the project, following general conclusion could be led. Conditional release levels for the most critical nuclides are usually up to one or two orders of magnitude higher compared with the limits for unconditional release defined according to the Slovak legislation [4]. It means 
several hundreds or thousands of $\mathrm{Bq} / \mathrm{kg}$ for radionuclides with the highest class of radiotoxicity e.g. ${ }^{60} \mathrm{Co},{ }^{137} \mathrm{Cs},{ }^{239} \mathrm{Pu}$ or ${ }^{241} \mathrm{Am}$.

The example of calculated mass of steel that could be released conditionally is presented on Figure 3 for inventory database of nuclear power plant of Russian type pressurized water reactor (VVER-440). It was assumed for the calculation that, conservatively, only one contaminant considered in the calculation belongs to the highest class of radiotoxicity (e.g. ${ }^{60} \mathrm{Co}-$ limit for unconditional release is $300 \mathrm{~Bq} / \mathrm{kg}$ ) [4].

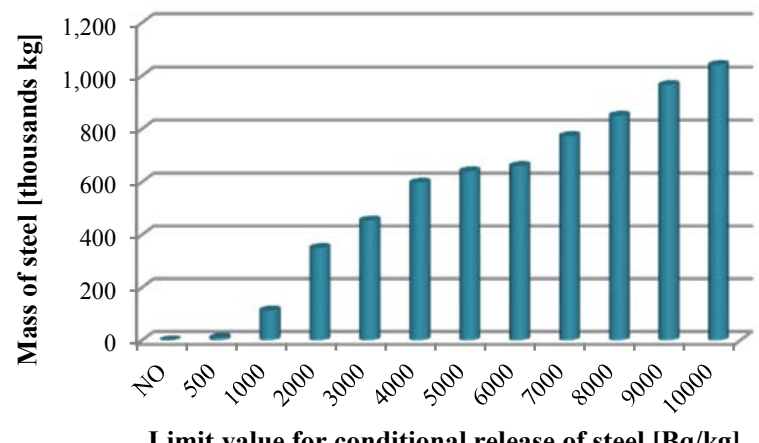

Figure 3. Mass of steel to be released conditionally.

Analyzing the results presented in Figure 3, it could be concluded that the mass of materials to be released conditionally varied in the interval of hundred thousand up to one million of kilograms. For the real cases including various nuclides with less restrictive unconditional release levels (e.g. ${ }^{63} \mathrm{Ni}$ or ${ }^{55} \mathrm{Fe}$ ) the amount of materials could be higher.

\section{Conclusion}

The paper presents complex methodology, developed within the research project CONRELMAT and implemented to the relevant calculation codes, for assessment of the options for conditional reuse of materials from nuclear installation decommissioning in industrial application. The assessment of the options is aimed to stipulate the conditional release levels $(\mathrm{Bq} / \mathrm{kg})$ for individual radionuclides, critical exposure pathway, critical group of persons and amount of materials to be released conditionally. The outputs and results of the evaluation of all the options defined in the project are gathered, creating the systematic general sample database (used procedures, developed methodology and numerical data). This database could be used in future as a source of information for possible real application of reusing the conditional released materials.

Generally speaking, the concept of conditional release could increase the amount of decommissioning materials to be recycled in a safe way without exceeding the legislatively defined limits for exposure of workers or the public. These materials are not treated as a radioactive waste and disposal capacity is saved. Prior to the real application of conditional release approach, it will be essential to discuss the issue with all relevant stakeholders (e.g. industry, government bodies, members of the public). Also, it is necessary to define the clear legislative framework.

\section{Acknowledgements}

This project has been partially supported by the Ministry of Education by decree No. CD-2009-36909/39460-1:11 within the bounds of project CONRELMAT.

\section{References}

[1] V. Daniska and V. Necas, Calculation modeling of the decommissioning process of nuclear installations, Journal of Electrical Engineering, Vol. 51, No. 5-6, (2000), pp. 156-167, ISSN 1335 3632.

[2] OECD/NEA, Release of Radioactive Materials and Buildings from Regulatory Control, Paris, (2008), ISBN 978-92-64-99061-6.

[3] International Atomic Energy Agency, Application of the Concepts of Exclusion, Exemption and Clearance, Safety Guide No. RS-G-1.7, Vienna, (2004), ISBN 92-0-109404-3.

[4] Statutory Order No. 345/2006 on the Basic Safety Requirements on Personnel and Public Health Protection against Ionizing Radiation (in Slovak).

[5] International Atomic Energy Agency, Managing Low Radioactivity Material from the Decommissioning of Nuclear Facilities, Technical report series No.462, Vienna, (2008).

[6] V. Daniska, J. Pritrsky, F. Ondra, M. Zachar and V. Necas, Reuse of Conditionally Released Materials from Decommissioning; A Review of Approaches and Scenarios with Long-Term Constructions, Proceedings of the 14th International Conference on Environmental Remediation and Radioactive Waste Management, September 25-29, 2011, Reims, France, (2011). [CD-Rom]

[7] T. Hrncir and V. Necas, Radiation Impact of Very Low Level Radioactive Steel Reused in Motorway Tunnel Constructions, Paper presented on ICRS-12, September 2-7, 2012, Nara, Japan, (2012).

[8] International Atomic Energy Agency, Derivation of Activity Concentrations Values for Exclusion, Exemption and Clearance, Safety Reports Series No.44, Vienna, (2005).

[9] M. Zachar, V. Daniska and V. Necas, Improved analytical methodology for calculation assessment of material parameters in the nuclear installation decommissioning process, Progress in Nuclear Energy, Vol.53, Issue 5, (2011), pp.463-470.

[10]M. Panik and V. Necas, Long-Term Radiation Impact of Conditionally Cleared Radioactive Material from Decommissioning of Nuclear Power Plants Reused in Building Industry, Paper presented on ICRS-12, September 2-7, 2012, Nara, Japan, (2012). 
[11]M. Novak, J. Pritrsky, V. Daniska and P. Juhar, Conditional Clearance of Radioactive Demolition Waste in Motorway Scenario, Paper presented on
ICRS-12, September 2-7, 2012, Nara, Japan, (2012). 